\title{
A Educação do Campo: um estudo sobre as condições das escolas dos assentamentos de Reforma Agrária
}

\author{
The Field Education: a study on the conditions of schools in Agrarian \\ Reform settlements
}

Vitor Machado

Doutor em Educação

Universidade Estadual Paulista "Júlio de Mesquita Filho" - UNESP.

Bauru, SP - Brasil.

v.machado@unesp.br

\author{
Amanda Matheus Tsuchiya \\ Graduanda em Pedagogia \\ Universidade Estadual Paulista "Júlio de Mesquita Filho" - UNESP. \\ Bauru, SP - Brasil. \\ amanda.tsuchiya@unesp.br
}

Resumo: A Educação do Campo surge no Brasil como resultado do processo de luta dos movimentos sociais do campo, especialmente do Movimento dos Trabalhadores Rurais Assentados (MST) Assim, esse trabalho tem como objetivo demonstrar que apesar das políticas públicas para a educação do campo ter representado grandes avanços, a realidade atual das escolas rurais revela a existência de um abismo entre tais políticas e os desafios educacionais a serem enfrentados pelas escolas da zona rural. Análises realizadas à luz do Censo da Educação Escolar de 2018 (BRASIL, 2019) revelam a grande precarização da infraestrutura dessas escolas e o fechamento de um número significativo delas nos últimos anos. Todos esses problemas apontados, como resultado do abandono dos nossos governantes, causam grandes dificuldades ao processo de ensino aprendizagem dos alunos do campo e contribuem também para que um significativo número de crianças e jovens da zona rural permaneça fora da escola.

Palavras chave: educação do campo; escola do campo; educação rural.

Abstract: Field Education arises in Brazil as a result of the struggle process of rural social movements, especially the Settled Rural Workers Movement (MST). Thus, this work aims to demonstrate that despite public policies for rural education, major advances, the current reality of rural schools reveals the existence of a chasm between such policies and the educational challenges to be faced by schools in rural areas. Analyzes carried out in the light of the 2018 School Education Census (BRASIL, 2019) reveal the great precariousness of the infrastructure of these schools and the closing of a significant number of them in recent years. All these problems pointed out, as a result of the abandonment of our governors, cause great difficulties in the teaching and learning process of rural students and also contribute to a significant number of children and young people in rural areas remaining out of school.

Keywords: field education; field school; rural education.

Cite como

(ABNT NBR 6023:2018)

MACHADO, Vitor; TSUCHIYA, Amanda Matheus. A Educação do Campo: um estudo sobre as condições das escolas dos assentamentos de reforma agrária. Dialogia, São Paulo, n. 39, p. 1-18, e20594, set./dez. 2021. Disponível em: https://doi.org/10.5585/39.2021.20630.

American Psychological Association (APA)

Machado, V., \& Tsuchiya, A. M. (2021, set./dez.) A Educação do Campo: um estudo sobre as condições das escolas dos assentamentos de reforma agrária. Dialogia, São Paulo, 39, p. 1-18, e20738. https:/ /doi.org/10.5585/39.2021.20630. 


\section{Introdução}

O projeto de Educação do Campo surge no final do século XX, decorrente das críticas dos trabalhadores rurais sobre a precariedade pedagógica e ao abandono em que estavam submetidas às escolas nas áreas de acampamento e assentamentos de Reforma Agrária. Os movimentos sociais e sindicais do campo, dentre eles o Movimento dos Trabalhadores Rurais Sem-Terra (MST), pressionam as instâncias do governo, reivindicando uma educação de qualidade, pertinente às necessidades dos trabalhadores pobres da zona rural. É a partir da luta travada por eles que se observa a implantação de políticas públicas e de programas de formação inicial e continuada de educadores atuantes no campo, destacando-se o Programa Nacional de Educação na Reforma Agrária (Pronera), o Programa de Apoio à Formação Superior em Educação do Campo (Procampo) e o Programa Nacional de Educação do Campo (Pronacampo).

Esta pesquisa tratou de mostrar a importância da implementação, para os trabalhadores rurais assentados, das políticas públicas e dos programas para a Educação do Campo para depois, à luz da análise dos dados extraídos do Censo Escolar (2018) (BRASIL, 2019), demonstrar a existência de um grande abismo entre tais políticas e os desafios educacionais enfrentados pelas escolas da zona rural.

Como resultado, o exame criterioso dos dados revelou que há uma precariedade de infraestrutura muito maior nas Escolas do Campo em comparação com os colégios da cidade. Além disso, constatou-se também que, entre 2016 e 2018, o número de escolas fechadas na zona rural superou a quantidade de estabelecimentos de ensino fechados em todo o território nacional.

Nesse sentido, há grande necessidade de que as políticas públicas de Educação do Campo sejam intensificadas, promovendo ações afirmativas para a formação inicial e continuada de docentes que atuam em Escolas do Campo. Elas podem ser de grande valia para o avanço de direitos das populações camponesas que produzem seus modos de vida a partir do meio rural e também servirão para auxiliar na estruturação de uma educação escolar mais inclusiva, democrática e de qualidade.

\section{Discutindo o conceito de Educação do Campo}

A Educação do Campo conceitua-se por seus pressupostos e diretrizes discutidas e implementadas a partir das práxis dos sujeitos coletivos presentes no meio agrícola. Sua gênese está relacionada ao protagonismo dos trabalhadores rurais assentados e suas organizações, os quais sempre buscaram uma forma de educação orgânica relacionada aos seus interesses. Essa educação 
idealizada pelo MST e outros atores políticos visa uma escola que esteja presente em sua localidade geográfica, rompendo a fronteira entre população atendida e a formatação escolar.

Caldart (2004) discorre que o conceito de Educação do Campo tem raiz tanto na sua materialidade de origem, surgindo a partir das críticas dos camponeses, que alertavam sobre a precariedade e o abandono aos quais estavam submetidas às Escolas do Campo, como no movimento histórico da realidade a que se refere, sendo necessário buscar apreender as contradições e tensões que estão presentes na concretude que a produziu e que a move. Segundo Caldart (2009, p. 3), a natureza e o destino da Educação do Campo estão

[...] profundamente ligados ao destino do trabalho no campo e, consequentemente, ao destino das lutas sociais dos trabalhadores e da solução dos embates de projetos que constituem a dinâmica atual do campo brasileiro, da sociedade brasileira, do mundo sob a égide do capitalismo em que vivemos. E ainda que 'muitos não queiram', esta realidade exige posição (teórica sim, mas sobretudo prática, política) de todos os que hoje afirmam trabalhar em nome da Educação do campo.

Os documentos elaborados pelo MST apontam que os objetivos e princípios da pedagogia a ser desenvolvida nas escolas de acampamentos e assentamentos de Reforma Agrária preconizam que os professores do assentamento tenham clareza quanto aos objetivos da Educação do Campo, vinculando a discussão metodológica da ação educativa ao processo de conhecimento do coletivo do Assentamento (MST, 2005). Isso significa valorizar a experiência de vida e o cotidiano das crianças Sem-Terra e de suas famílias, priorizando um ensino que passa pela organização coletiva do trabalho pedagógico e pela alfabetização dos alunos a partir da realidade (MACHADO, 2015).

Em relação à Escola do Campo

\begin{abstract}
Há bem mais coisas em jogo quando se discutem como devem ser os processos de gestão da escola ou de um curso, porque eles passam a ser compreendidos como um processo de formação humana. Representam a materialização das relações sociais capazes de fazer emergir determinados comportamentos, em torno dos quais se identificam valores, convicções, heranças culturais e que, ao serem explicitados, mostram aos educadores qual deve ser a ênfase de sua ação pedagógica. (CALDART, 2004, p. 290)
\end{abstract}

Nesse contexto, na gênese do compromisso/decisão com a educação escolar assumida pelo MST, houve uma progressiva ruptura com um conceito mais tradicional de escola. Na verdade, buscou-se uma aproximação com a formação humana de membros de uma organização de massas com os objetivos e princípios do MST, que visavam à articulação nacional da luta pela terra e por um projeto popular de desenvolvimento para o Brasil (CALDART, 2004). Passa-se a perceber que era necessária uma Escola do Campo, vinculada aos desafios que estavam colocados na realidade objetiva dos assentamentos. (CALDART, 2004) 
Conforme apontam documentos produzidos pelo MST (2005), é necessária uma educação escolar que permita transformar a realidade e pela qual se aprenda a enfrentar os problemas concretos que existem no assentamento. Ela deve intervir no cotidiano e construir na prática um novo projeto de campo e de sociedade discutido e defendido pelo Movimento a partir de uma perspectiva social mais ampla.

A Escola do Campo, nessas circunstâncias, deve fazer uma relação entre educação e produção, buscando modificar o mundo de forma concreta e enfrentar os problemas a partir de uma conjuntura social (MST, 2005). É necessário que haja, além de um plano teórico, um posicionamento político dos envolvidos com a Educação do Campo, reafirmando a luta pela superação do modo capitalista de produção, que privilegia as monoculturas, o agronegócio e as relações mercantis, a partir das relações de classe, visando adotar os princípios organizativos que os movimentos sociais reivindicam, em um novo modelo de desenvolvimento do campo, a partir de novas formas de produção e de trabalho.

Para Oliveira e Machado (2020, p. 254), o ponto fundamental da Escola do Campo é

incentivar o aluno a compreender a complexidade da realidade. É fazer com que ele não apenas aprenda cálculos e letras, mas o instigue a pensar, buscar a história de sua vida, os conflitos, as razões do preconceito contra os moradores do campo, a valorização do trabalho rural, a dignidade e a justiça.

Molina e Antunes-Rocha (2014) analisam que ao final da década de 1980, frente à precariedade física e pedagógica, com professores decorrentes da má formação ou ausência de qualificação necessária ao exercício da profissão, os movimentos sociais e sindicais agrários passaram a reivindicar do governo a criação de Escolas do Campo e a formação de docentes qualificados, conforme as necessidades do contexto de atuação.

No início dos anos 1990, uma nova discussão começa a ser processada no Movimento: o da identidade compartilhada do MST com as Escolas do Campo, pois se o que está em jogo é um novo projeto de desenvolvimento e o futuro das gerações de camponeses, é preciso estabelecer novos vínculos e integrar outros elementos à discussão pedagógica. (CALDART, 2004)

Como desdobramentos desse processo de debates e alianças estabelecidas, surgem diversos programas como o Programa Nacional de Educação na Reforma Agrária (Pronera) - ligado ao Ministério do Desenvolvimento Agrário -, o Programa de Apoio à Formação Superior em Licenciatura em Educação do Campo (Procampo) e o Programa Nacional de Educação do Campo (Pronacampo), ambos vinculados ao Ministério da Educação. Esses projetos são resultados das conquistas realizadas a partir do engajamento dos movimentos sociais do campo a fim de garantir aos assentados rurais o direito de acesso e conclusão da educação em seus vários níveis. 
Conforme Carneiro, Afonso e Mesquita (2016, p. 233), essa luta dos trabalhadores por educação configura-se como "[...] luta política de classe, em busca de formação profissional e por melhores condições de vida, como possibilidades instrumentais no enfrentamento da inserção produtiva no mundo do trabalho". A seguir, serão demonstrados como foram sendo implantados os programas citados enquanto políticas públicas para a Educação do Campo.

\section{A Educação do Campo como política pública}

Em 1997, ocorreu o I Encontro Nacional das Educadoras e Educadores da Reforma Agrária $^{1}$, celebrando os 10 anos de criação do Setor de Educação do Movimento dos Trabalhadores Rurais Sem-Terra (MST). Identificou-se, naquele encontro, a participação de dezenas de universidades com experiências genuínas com a educação na reforma agrária e percebeu-se a necessidade de se realizar uma articulação entre esses parceiros, para avançar a escolarização nos assentamentos, cujos índices revelados pelo I Censo Nacional da Reforma Agrária (FERRANTE; BERGAMASCO, 1995), concluído em 1995, eram extremamente baixos. A partir daí, começaram a se construir inúmeras articulações que viriam a resultar na criação do Programa Nacional de Educação na Reforma Agrária (Pronera) (MOLINA, 2017; MOLINA, ANTUNES-ROCHA, 2014). Esse momento foi marcado por muita luta, mas também por inúmeros desentendimentos, no qual o MST teve papel relevante e decisivo, dada a pressão por ele orquestrada para a estruturação e liberação orçamentária ao Programa. Dentro desse contexto de disputas, após várias negociações, o Pronera é instituído em 1998, estando atrelado, inicialmente, ao já extinto Ministério da Política Fundiária. Anos depois, em 2001, ele passa para o Instituto Nacional de Colonização e Reforma Agrária (INCRA).

O principal objetivo do Pronera se constitui como mecanismo em favor da democratização da educação para os trabalhadores/as da reforma agrária, respeitando as particularidades dos sujeitos sociais e, paralelamente, contribuindo para a permanência dos agricultores no campo, tendo o desenvolvimento sustentável como principal resultado desse processo. (SANTOS; SILVA, 2016, p. 4)

O Pronera surge como um meio de democratizar o acesso à educação, no que tange à alfabetização e escolarização de jovens e adultos, à qualificação de educadores para as escolas de assentamentos de Reforma Agrária e também no tocante à formação técnica-profissional de nível médio e superior. Além de organizar, produzir e editar os materiais didático-pedagógicos necessários, a execução do programa teve como seu principal objetivo efetivar políticas de

\footnotetext{
${ }^{1}$ Esse encontro pode ser considerado a vanguarda do debate da Educação do Campo no Brasil. A amplitude do seus debates resultou no encaminhamento político das Diretrizes Operacionais para a Educação Básica das Escolas do Campo.
} 
educação em todos os níveis nas áreas de Reforma Agrária. Enquanto política pública, o Pronera se fundamenta no desenvolvimento, a partir da gestão participativa, e na descentralização das ações das instituições públicas envolvidas com a educação, contando com a coparticipação dos movimentos sociais e sindicais de trabalhadores rurais, instituições de pesquisa, governos estaduais e municipais (BRASIL, 2004). Conforme Molina e Antunes-Rocha (2014, p. 230), no período de 1998 a 2014, “[...] cerca de 200 mil trabalhadores rurais se escolarizaram nos diferentes níveis de ensino: da alfabetização à conclusão dos ensinos fundamental e médio, aos cursos técnicos e profissionalizantes e aos cursos superiores". Além disso, de acordo com as autoras, mais de 60 universidades assumiram parceria com o Pronera e mais de 200 convênios foram firmados neste período.

Uma das principais características do Pronera é o enfrentamento feito pela unificação ao direito e pelo reconhecimento da diversidade dos povos do campo, estabelecendo como concepção de política pública a participação coletiva desse segmento da população e a universalização do direito à diversidade que eles possuem.

Esta diversidade teve reconhecimento por meio da publicação do Decreto n. ${ }^{\circ}$ 7.352, de 4 de novembro de 2010, no qual o Estado brasileiro integra o Pronera à política pública de Educação do Campo (art.11. ${ }^{\circ}$ ). O Decreto 7.352 representa um marco na história da educação do campo, uma vez que conceitua as populações camponesas e define escola do campo. (SANTOS; SILVA, 2016, p. 5)

Um importante documento de execução do Pronera é o seu Manual de Operações. Nele constam os pressupostos da sua proposta pedagógica que, na verdade, se constituem como princípios orientadores e norteadores para todos os níveis de ensino, tais como: o princípio do diálogo, que deve garantir uma dinâmica capaz de assegurar a valorização de diferentes saberes e a produção coletiva do conhecimento; o princípio da práxis, que coloque em perspectiva o movimento de ação-reflexão-ação e a transformação da realidade, propiciando aos educandos/educandas estarem envolvidos em ações sociais concretas; o princípio da transdisciplinaridade, contribuindo para a articulação de todos os conteúdos e saberes locais, “[...] garantindo livre trânsito entre um campo de saber e outro" (BRASIL, 2004, p. 27). Com relação a esse manual, Diniz (2005) aponta que entre 1998 e 2014 foram publicados cinco manuais de operações para regulamentar as ações do Pronera, os quais passaram a controlar a participação dos movimentos sociais do campo, contribuindo gradativamente para afastá-los das decisões relativas ao programa, juntamente com diferentes entidades da sociedade civil. Se por um lado o Pronera, enquanto uma política de Estado, ganha maior abrangência, por outro perde a radicalidade e se afasta do movimento de origem. Seria ingenuidade acreditar que esse processo de adentramento 
no campo, das políticas públicas, ocorreria sem maiores repercussões, constituindo-se como prática "neutra".

Mas a experiência do Pronera acumulada ao longo dos anos, nos mais diversos âmbitos de abrangência, influenciou diretamente na geração de novas políticas públicas visando a formação e qualificação de sujeitos para aturem na Educação do Campo. Dentre elas, vale destacar a criação, em 2011, do Programa de Apoio à Formação Superior em Licenciatura em Educação do Campo (Procampo) pelo Ministério da Educação (MEC) e por iniciativa da Secretaria de Educação Continuada, Alfabetização e Diversidade (SECAD). Esse Programa

[...] surge por meio de parcerias com as Instituições Públicas de Ensino Superior e objetiva viabilizar a criação de cursos de Licenciatura em Educação do Campo, a fim de promover a formação de educadores/as, por área de conhecimento, para atuarem junto às escolas do campo na educação básica. (SANTOS; SILVA, 2016, p. 6)

O documento que versa sobre o Procampo indica que os projetos devem apresentar organização curricular por etapas equivalentes há semestres regulares cumpridas em Regime de Alternância entre Tempo-Escola e Tempo-Comunidade; estabelecer condições metodológicas e práticas para que os educadores em formação possam tornar-se agentes efetivos na construção e reflexão dos projetos político-pedagógico das Escolas do Campo; apresentar currículo organizado de acordo com áreas de conhecimento previstas para a docência multidisciplinar - (i) Linguagens e Códigos; (ii) Ciências Humanas e Sociais; (iii) Ciências da Natureza e Matemática e (iv) Ciências Agrárias, e com duas áreas de habilitação; considerar a realidade social e cultural específica das populações a serem beneficiadas, devendo ser elaborados com a participação dos Comitês/Fóruns Estaduais de Educação do Campo, onde houver, e dos sistemas estaduais e municipais de ensino. (MEC, 2008)

As primeiras experiências de Licenciatura em Educação do Campo iniciaram em 2007, como projeto piloto, em quatro universidades: Universidade Federal de Brasília (UNB), Universidade Federal da Bahia (UFBA), Universidade Federal de Minas Gerais (UFMG), Universidade Federal de Sergipe (UFS). Estes projetos foram considerados turmas especiais, com financiamento próprio e com maior autonomia de elaboração dos projetos políticos pedagógicos dos cursos. Posteriormente, estes cursos entraram na lógica das políticas públicas regidas por editais e efetivadas por programas através do Procampo e Pronacampo.

Já o Programa Nacional de Educação do Campo (Pronacampo) foi criado pelo Decreto n. ${ }^{\circ}$ 7.352 e instituído por meio da Portaria n. ${ }^{\circ}$ 86, de 1. ${ }^{\circ}$ de fevereiro de 2013 (BRASIL, 2001). Lançado em 2012, teve como objetivo oferecer financiamento técnico que pudesse colocar em prática as políticas públicas para a Educação do Campo em todo o território nacional. Além disso, visava 
assegurar a melhoria do ensino nas Escolas do Campo, promover a qualificação docente, a produção de material didático específico e o investimento em infraestrutura, baseado em quatro principais eixos de atuação, sendo eles: a) Eixo I - Gestão e Práticas Pedagógicas; b) Eixo II Formação de Professores; c) Eixo III - Educação de Jovens e Adultos, Educação Profissional e Tecnológica; d) Eixo IV - Infraestrutura Física e Tecnológica (MARTINS, 2020). Todavia, conforme apontam Santos e Silva (2016), a ausência do protagonismo conferido aos movimentos sociais agrários na elaboração de ações, como se fez para gerir os programas anteriores, afastou o Pronacampo dos interesses necessários à Educação do Campo.

Enfim, os conflitos ideológicos, técnicos e administrativos fizeram com que os projetos e intenções originárias sofressem alterações e adaptações para poderem ser aprovados e reconhecidos pela estrutura universitária e pelo próprio Ministério da Educação (MEC) e pela Coordenação de Aperfeiçoamento de Pessoal de Nível Superior (Capes). A partir do momento em que os cursos passam de especiais para regulares nas universidades, as dificuldades e a perda de autonomia político-pedagógica na elaboração dos projetos são ainda maiores pela necessidade de adequação à estrutura universitária e às questões burocráticas (D’AGOSTINI; TITTON, 2014).

Cabe expor ainda que no caso da Educação do Campo, seu atendimento via políticas públicas é praticamente restrito a programas de governo, sem perspectiva de continuidade, instaurados na forma de decretos, programas e editais (D'AGOSTINI; TITTON, 2014). Essa lacuna leva o governo brasileiro a instituir, em 2020, o Decreto n. 20.252 (BRASIL, 2020) que enxuga, significativamente, o INCRA, extinguindo a Coordenação responsável pela Educação do Campo. Isso veio impossibilitar a continuidade de programas como o Pronera, responsável por formar 164.894 camponeses e camponeses nos 27 estados da federação, no período de 1998 a 2011. (D'AGOSTINI; TITTON, 2014)

Embora a LDB 9394/96 (BRASIL, 1996), no seu artigo 28, já estabelecesse diretrizes para a educação básica para o campo, afirmando a legitimidade às adaptações do ensino, com conteúdos curriculares e metodologia, adequações no calendário escolar e adequação à natureza do trabalho, de acordo com as especificidades da vida rural e de cada região (BRASIL, 1996), é com a aprovação das "Diretrizes Operacionais para a Educação Básica nas Escolas do Campo" (BRASIL, 2002), em 2002, e sua complementação por meio da Resolução CNE/CEB n. ${ }^{\circ}$ 2, de 28 de abril de 2008 (BRASIL, 2008), que esse tema passa a ser abordado de forma mais profunda. Tais documentos passaram a regulamentar as primeiras políticas públicas de Estado voltadas para a Educação no Campo. Essas políticas englobam as diferentes etapas da Educação "destinando-se aos agricultores familiares, extrativistas, pescadores artesanais, ribeirinhos, assentados e acampados da Reforma 
Agrária, quilombolas, caiçaras, indígenas e outros" (BRASIL, 2008) e preconizam que a escola deve estar ancorada na realidade dos alunos, em suas diferentes formas de produção de vida, valorizar seus saberes e a memória coletiva, tendo um elo com os movimentos sociais que defendem projetos visando à qualidade da vida social e o desenvolvimento de um país que tenha como paradigma a justiça social, a solidariedade e o diálogo entre todos (BRASIL, 2002). Além disso, o documento ressalta ainda a importância da articulação entre escola e trabalho, considerando como indispensável o apoio pedagógico em conformidade com a realidade local e as diversidades dos povos do campo. Ele destaca também a organização e o funcionamento das escolas respeitandose as diferentes entre as populações atendidas (atividade econômica, estilo de vida, cultura e tradições). (BRASIL, 2008).

\section{Educação do Campo: um panorama sobre a realidade das escolas rurais}

A partir da Lei de Diretrizes e Bases da Educação Nacional (LDB) (BRASIL, 1996), aprovada em 1996, e os documentos dela decorrentes, há uma mudança de vocabulário, pois os termos "escola rural" e "escola do campo" passaram a ter conotações distintas. O conceito campo passou a ter uma conotação diferente da anterior, já que era entendido enquanto região fora do perímetro urbano, e passa a ser caracterizado como a ligação dos seres humanos com as próprias condições de existência social. Essa alteração conceitual também representa uma mudança paradigmática na educação escolarizada e defende outras ideias acerca da formação docente (VIGHY, 2015).

Apesar das políticas públicas formuladas especificamente para as populações do campo, dados do INEP (2007) (BRASIL, 2007), sobre o ano de 2005, mostravam já naquele momento, que $75 \%$ dos professores que atuavam nas séries iniciais do Ensino Fundamental (1.a a 4. ${ }^{\text {a }}$ série ${ }^{2}$ nas áreas rurais, possuíam formação de nível médio completo e que apenas 21,6 \% dos professores dessas escolas tinham formação superior, enquanto que nas escolas urbanas essa porcentagem correspondia a 56,4 \% dos docentes. Ainda segundo dados do INEP (2007) (BRASIL, 2007), nas séries finais do Ensino Fundamental (5. a 8. ${ }^{a}$ série $)^{3}$, o percentual de docentes com apenas o Ensino Médio completo correspondia a 46,7\% do total, e apenas 53,1\% possuíam Ensino Superior completo. Nas escolas urbanas, esses números eram de 12,5\% e 87,5\%, respectivamente. Esse mesmo documento indica também que a remuneração dos professores das

\footnotetext{
${ }^{2}$ Atualmente, as séries iniciais do Ensino Fundamental é composta do $1 .^{\circ}$ ao $5 .^{\circ}$ ano.

${ }^{3}$ Atualmente as séries finais do Ensino Fundamental é composta do $6 .^{\circ}$ ao $9 .^{\circ}$ ano.
} 
áreas rurais é bem inferior àquela percebida pelos seus colegas que lecionam em escolas urbanas (BRASIL, 2007).

Nesse contexto, fica evidente a necessidade de se implantar e acompanhar, no âmbito da esfera pública, ações para que os professores das Escolas do Campo recebam qualificação adequada, como exposto no Parágrafo Único, do Artigo 12, da Resolução CNE/CEB 1, de 3 de Abril de 2002 (BRASIL, 2002). Tal artigo prevê a formação inicial em curso de licenciatura como qualificação mínima para exercer a docência na Educação Infantil e nos anos iniciais do Ensino Fundamental, conforme regulamentado em seu parágrafo único: “Os sistemas de ensino, de acordo com o artigo 67 da LDB desenvolverão políticas de formação inicial e continuada, habilitando todos os professores leigos e promovendo o aperfeiçoamento permanente dos docentes" (BRASIL, 2002, p. 2).

Apesar da formulação das políticas públicas para a Educação do Campo terem avançado nos últimos anos, ainda é recorrente o desconhecimento delas pelos profissionais da educação, que trabalham em Escolas do Campo, sejam eles gestores e/ou professores (ADDISON, 2019). Conforme estudo desenvolvido por Addison (2019), a falta de conhecimento por parte desses profissionais da educação, acerca da legislação e dos marcos normativos que regulamentam a Educação do Campo, tem contribuído para fortalecer os princípios e a lógica do capital que priorizam a cultura dominante, notadamente urbana e mercadológica. Isso enfraquece o enraizamento das novas gerações assentadas, fortalecendo o movimento de saída dos jovens em direção às cidades à procura de emprego, uma vez que a escola não lhes garante perspectiva de vida no assentamento (ADDISON, 2019). Associado a isso está o problema do material didático utilizado pela Escola do Campo. Addison (2019) demonstrou que seu uso é descontextualizado da realidade interferindo no processo pedagógico e na formação da identidade dos alunos assentados. Sobre esse assunto, cabe destacar também a pesquisa realizada por Ravaneli (2019) ao analisar um dos livros didáticos, do Programa Nacional do Livro e do Material Didático/Campo (PNLD Campo) (2016-2018), utilizado no 5. ano do Ensino Fundamental, das Escolas do Campo. Segundo relata, o livro didático analisado está completamente desvinculado do processo de ensinoaprendizagem, deixando de ser elemento fundamental do currículo, por não complementar as práticas educativas inerentes ao ambiente escolar propício à Escola do Campo. Neste caso, Oliveira e Machado (2000) chamam atenção para a necessidade dessa escola superar o modo como a educação vem sendo nela praticada, eliminando do seu universo ações discriminatórias, exploratórias e de reprodução de classes sociais. Conforme eles dizem, isso seria possível com o desenvolvimento de uma prática pedagógica em que conhecimento e trabalho caminhem juntos. 
A escola do campo "[...] ao ter o trabalho como um princípio educativo, promove a simbiose entre o meio e o conteúdo escolar, permitindo que o aluno tenha uma lúcida compreensão da realidade". (OLIVEIRA; MACHADO, 2000, p. 255)

Quando se analisa atentamente as diferenças de infraestrutura entre as Escolas do Campo e as escolas da cidade, é possível evidenciar uma escassez de recursos públicos destinados à Educação do Campo, fator este que pode ser relacionado não só ao projeto de esvaziamento e mecanização agrícola, mas também como causa que levou ao fechamento de um contingente enorme de escolas na zona rural. Em relação à estrutura física, dados recentes extraídos do Censo da Educação Básica de 2018 (BRASIL, 2019) evidenciam a existência de uma infraestrutura notadamente precária na Escola do Campo, com falta de recursos materiais e condições mínimas de higiene, quando comparado às escolas públicas das cidades. Os dados apontam que em 2018, de 84.344 escolas localizadas na área urbana, 74.819 (89\%) delas possuíam internet e havia 829.823 equipamentos para uso dos alunos, enquanto nas 56.954 escolas rurais, apenas 19.304 (34\%) tinham possibilidade de acesso a esse tipo de tecnologia, com 121.723 equipamentos para uso dos alunos. (BRASIL, 2019)

Com relação aos serviços disponíveis, enquanto em 93\% das escolas urbanas públicas há água encanada, 100\% têm acesso à energia, 65\% têm esgoto e em 99\% a coleta de lixo é periódica, nas Escolas do Campo esses números caem brutalmente. Só 30\% delas têm água via rede pública, $87 \%$ têm energia elétrica, apenas 5\% têm acesso a esgoto canalizado e somente $34 \%$ têm seu lixo coletado regularmente. (BRASIL, 2020)

No tocante aos espaços de aprendizagem presentes no ambiente escolar das Escolas do Campo, apenas 14\% (8.209 escolas) possuem biblioteca, 1\% (846 escolas) tem laboratório de ciências, 13\% (7.538 escolas) quadra de esportes e 8\% (4.800 escolas) dispõem de sala para atendimento especial. Já nas escolas públicas localizadas no espaço urbano, 42\% (35.360 escolas) têm biblioteca, 13\% (10.815 escolas) contêm laboratório de ciências, 46\% (38.626 escolas) têm quadra de esportes e 32\% (26.966 escolas) possuem sala de atendimento especial (BRASIL, 2020).

Realizando pesquisa em um estabelecimento de ensino da região do centro oeste paulista, que atende alunos provenientes de um assentamento rural, Oliveira (2017) demonstrou que a falta de investimentos em políticas públicas educacionais leva o estudante do campo a abandonar os estudos. Aqueles que permanecem, estudam em escolas precárias em termos de infraestrutura, sem condições mínimas de higiene e alimentação, tendo que conviver diariamente com um ambiente muito desfavorável para uma aprendizagem de qualidade. (OLIVEIRA, 2017) 
Sobre o fechamento de Escolas do Campo e seus impactos, Andrade, Filho e Faria (2020), ao analisarem os dados estatísticos referentes ao Censo Escolar (2014) (BRASIL, 2014) e Censo da Educação Básica (2018) (BRASIL, 2019), concluem que entre os anos de 2014 e 2018, mais de 9.945 escolas localizadas em áreas rurais foram fechadas, seguindo um ritmo próximo da década anterior. Conforme os autores, a justificativa dos governantes para isso foi o argumento de que o ensino ministrado em classes multisseriadas era de muito baixa qualidade, além do fato dela ser frequentada por um pequeno número de alunos, o que representa baixa vinculação de recursos públicos. Esse fator alia-se à tendência que as Secretarias Estaduais de Educação vêm adotando ao agrupar essas pequenas escolas multisseriadas em uma escola núcleo, algumas vezes situadas em áreas urbanas e comumente mais longe da residência dos estudantes.

No que tange ao fechamento de escolas na zona rural, Oliveira e Machado (2020), ao analisarem dados do Censo da Educação Básica entre os anos de 2016 e 2018, constataram também que foram fechadas neste período 7.742 escolas na zona rural, ultrapassando o número total de 5.490 estabelecimentos fechados em todo o território nacional, número que só não foi ainda maior pelo fato do governo federal ter criado no mesmo período 2.255 escolas urbanas. Para os autores, a extinção desse número considerável de escolas na zona rural mostra o total descaso dos nossos governantes frente ao atendimento das políticas públicas destinadas a atender a Educação do Campo no nosso país.

O impacto causado pela falta de investimentos em infraestrutura e o fechamento das escolas na zona rural afetam diretamente as crianças pobres do campo, principalmente, aquelas em fase pré-escolar (creche e pré-escola) e as que possuem idade para cursar as séries iniciais e finais do Ensino Fundamental. Dados do Censo da Educação Básica de 2018 (BRASIL, 2019) mostram que naquele ano foram matriculadas na Educação Infantil, em escolas da zona rural, 899.544 crianças. Em 2020, esse número caiu para 895.413 (BRASIL, 2021) mostrando que no período de dois anos houve uma redução de 4.131 matrículas somente na Educação Infantil. Analisando também a quantidade de matrículas realizadas nas séries iniciais e finais do Ensino Fundamental, em 2018, elas totalizaram 3.666.757 (BRASIL, 2019), enquanto que em 2020, esse número decaiu para 3.424.173 crianças matriculadas (BRASIL, 2021). Neste último caso, o número de matrículas não efetivadas nas séries iniciais e finais do Ensino Fundamental chegou a 242.584. Somando-se então o número de matrículas não concretizadas, entre 2018 e 2020, tanto na Educação Infantil quanto no Ensino Fundamental, o número de crianças entre 0 e 14 anos que deixaram de ser atendidas pela escola foi de 246.715. Tais dados demonstram claramente a necessidade urgente de se intensificar as políticas de Educação no Campo para que essas crianças sejam incluídas pela 
escola. Somente a consolidação delas poderá levar à concretização de ações mais efetivas que garantam o direito de se ter escolas que expressem as necessidades cotidianas da população pobre habitante da zona rural.

O fato é que não é só em relação às crianças que os números preocupam. No Brasil, em 2018, foram realizadas, em Escolas do Campo, 1.394.971 matrículas (BRASIL, 2019) nos anos finais do Ensino Fundamental, número que não se repete na etapa posterior, quando a criança entre na sua fase juvenil e deveria avançar para o Ensino Médio. No entanto, em 2020, foram constatadas no Ensino Médio somente 470.513 matrículas (BRASIL, 2021), sendo 374.823 delas efetivadas no Ensino Médio regular e outras 95.690 confirmadas em curso técnicoprofissionalizante da zona rural. Em pesquisa realizada no ano de 2018, no assentamento Dandara, na cidade de Promissão-SP, Alves (2019) afirma que os jovens ao encerrarem o Ensino Fundamental em escolas do assentamento buscam concluir o Ensino Médio em estabelecimentos educacionais públicos localizados na cidade. Quando chegam lá, passam a sofrer uma série de preconceitos tanto por parte de alunos como dos professores. Os dados apontados por Alves (2019) revelam claramente que o debate sobre a Educação do Campo precisa avançar para um cenário que muitas vezes não é visto a olho nu, mas que faz parte do universo dos jovens assentados. É necessário que surjam ainda mais políticas públicas que impulsionem a capacidade desse jovem, em específico, de se reinventar em novos espaços. No entanto, não se pode perder de vista a necessidade que a Escolas do Campo têm no processo de formação daqueles que dela carecem.

Portanto, os números mostram que muito ainda tem de ser feito para a efetivação das políticas públicas para a Educação do Campo. Sua efetivação depende do esforço muito grande daqueles que têm o compromisso com ela, no sentido de buscar caminhos e construir alternativas que levem os problemas aqui apontados a serem mais facilmente superados.

\section{Considerações Finais}

Conforme discutido ao longo deste texto, o projeto de Educação do Campo surge frente à precariedade e abandono ao qual as escolas rurais foram historicamente submetidas. Ele foi construído com o protagonismo dos movimentos sociais e sindicais, destacadamente o Movimento dos Trabalhadores Rurais Sem-Terra (MST).

Após algumas experiências iniciais em acampamentos e assentamentos de Reforma Agrária, os trabalhadores do campo passam a perceber que não bastava uma escola no assentamento, mas que era necessária uma escola de assentamento, com um projeto pedagógico orgânico, voltado aos 
interesses dos camponeses e vinculada aos desafios que estavam colocados na sua realidade objetiva, ou seja, um projeto pedagógico e metodológico com grande vinculação às práticas e teorias da educação popular e com grande influência das perspectivas socialistas/emancipatórias de educação.

Foram as pressões sociais decorrentes das ações dos movimentos sociais que possibilitaram avanços significativos no que tange à legislação e à aquisição de direitos sociais relacionados à Educação do Campo, em seus diferentes níveis de ensino. Além disso, houve um investimento no âmbito das políticas públicas para promover a qualificação dos professores que atuam no campo, fator de extrema importância, principalmente ao se levar em conta que muitos deles não possuem formação adequada. Daí a criação de programas como o Programa de Apoio à Formação Superior em Licenciatura em Educação do Campo - Procampo, responsável por uma formação docente mais crítica, popular e voltada às necessidades das comunidades de assentamentos de Reforma Agrária. O Procampo conseguiu ampliar as condições de formação em licenciaturas para professores oriundos do campo, o que se mostrou como um fator necessário e de extrema relevância frente à conjuntura das Escolas do Campo no Brasil. Todavia, em 2020, o Governo Federal, por meio do decreto n. 20.252 , restringiu significativamente as atividades do INCRA, extinguindo a Coordenação responsável pela Educação do Campo e impossibilitando a continuidade de programas como o PRONERA. Concomitante a isso, seguem sendo fechadas as Escolas do Campo em um ritmo acelerado, sob diferentes pretextos e justificativas, que buscam encobrir a perversidade do projeto que visa transformar o modelo urbano-industrial em hegemônico, atacando a permanência dos sujeitos do campo em seus lugares de vivência, assim como os patrimônios culturais por eles produzidos.

A falta de investimentos na Escola do Campo aprofundou as diferenças infraestruturais entre elas e as escolas urbanas, evidenciando uma escassez de recursos públicos destinados à Educação do Campo, o que tem levado ao fechamento de um número expressivo de escolas localizadas em áreas rurais.

Todo o descaso dos governantes com a Educação do Campo, evidenciado pela falta de infraestrutura e escassez de investimentos na formação de recursos humanos, tem produzido um grande impacto na escolarização de crianças e jovens da zona rural, pois muitos deles se encontram fora da escola. 


\section{Referências}

ADDISON, Cristiane Rizzo. A educaşão em assentamento rural e as perspectivas de uma formação emancipadora. 2019. 101 f. TCC (Graduação) - Curso de Pedagogia, Unesp, Bauru, 2019.

ALVES, Adaísa Adail. Jovens assentados: dilemas da educação básica no cotidiano rural do município de Promissão-SP. 2019. Dissertação (Mestrado em Mestrado Profissional em Docência para a Educação Básica) - UNESP - Câmpus de Bauru.

BRASIL. Edital no 2, de 23 de abril de 2008 - Chamada pública para seleção de projetos de instituições públicas de ensino superior para o PROCAMPO. MEC: Brasília Disponível em:

http://portal.mec.gov.br/arquivos/pdf/edital_procampo.pdf. Acesso em: 22 mar. 2020.

BRASIL. Instituto Nacional de Estudos e Pesquisas Educacionais Anísio Teixeira (Inep). Censo da Educação Básica 2019. Resumo Técnico: Brasília, 2020. Disponível em

https://www.gov.br/inep/pt-br/areas-de-atuacao/pesquisas-estatisticas-e-indicadores/censoescolar/resultadoso. Acesso em: 22 mar. 2020

BRASIL. Instituto Nacional de Estudos e Pesquisas Educacionais Anísio Teixeira (Inep). Censo da Educação Básica 2018. Resumo Técnico: Brasilia, 2019. Disponível em

https://www.gov.br/inep/pt-br/areas-de-atuacao/pesquisas-estatisticas-e-indicadores/censoescolar/resultadoso Acesso em: 22 mar. 2020

BRASIL. Instituto Nacional de Estudos e Pesquisas Educacionais Anísio Teixeira (Inep). Censo da Educação Básica 2020. Resumo Técnico: Brasília, 2021. Disponível em

https://www.gov.br/inep/pt-br/areas-de-atuacao/pesquisas-estatisticas-e-indicadores/censoescolar/resultadoso Acesso em: 22 mar. 2020

BRASIL. Instituto Nacional de Estudos e Pesquisas Educacionais Anísio Teixeira (Inep). Censo Escolar 2014. INEP: Brasília, 2014. Disponível em

https://www.gov.br/inep/pt-br/areas-de-atuacao/pesquisas-estatisticas-e-indicadores/censoescolar/resultadoso Acesso em: 22 mar. 2020

BRASIL. Lei no 9.394, de 20 de dezembro de 1996. Estabelece as diretrizes e bases da educação nacional. Diário Oficial da União, Brasília, 23 de dezembro de 1996. Seção 1, p. 27833.

BRASIL. Portaria n ${ }^{\circ} 86$, de $1^{\circ}$ de fevereiro de 2013. Institui o Programa Nacional de Educação do Campo - PRONACAMPO, e define suas diretrizes gerais. Diário Oficial da União, Brasília, 04 de fevereiro de 2013. Seção 1, p. 28.

BRASIL. Programa Nacional de Educação na Reforma Agrária-PRONERA: Manual de Operações. Edição revista e atualizada. Brasília, 2004.

BRASIL. Resolução CNE/CEB 1, de 3 de abril de 2002. Institui Diretrizes Operacionais para a Educação Básica nas Escolas do Campo. Diário Oficial da União, Brasília, 9 de abril de 2002. Seção 1, p. 32. 
BRASIL. Resolução CNE/CEB 1/2002. Diretrizes Operacionais para Educação Básica nas Escolas do Campo. Diário Oficial da União, Brasília, 9 de abril de 2002. Seção 1, p. 32. Disponível em: http:/ / portal.mec.gov.br/index.php?option $=$ com_docman\&view $=$ download\&alias $=13800$ rceb001-02-pdf\&Itemid=30192 Acesso em: 20 mar. 2019.

BRASIL. INEP. Panorama da educação no campo. Brasília: Instituto Nacional de Estudos e Pesquisas Educacionais Anísio Teixeira - Inep, 2007. Disponível em

https://download.inep.gov.br/publicacoes/institucionais/estatisticas_e_indicadores/panorama_ da_educacao_do_campo.pdf. Acesso em: 22 mar. 2020.

CALDART, Roseli Salete. Educação do campo: notas para uma análise de percurso. Trab. Educ. Saúde, Rio de Janeiro, v. 7 n. 1, p. 35-64, mar./jun.2009. Disponível em: < http://www.scielo.br/pdf/tes/v7n1/03.pdf> Acesso em: 20 mar. 2019

CALDART. Pedagogia do movimento Sem Terra. 3 ed. São Paulo: Expressão Popular, 2004 CARNEIRO, M. E. F.; AFONSO, L. H. R.; MESQUITA, M. C. das G. D. Educação e Política Pública: caminhos históricos do Pronera. EDUCATIVA (GOIÂNIA. ONLINE), v. 19, p. 233258, 2016. Disponível em: file:// C:/Users/Vitor/Downloads/38695-Texto\%20do\%20Artigo130993-1-10-20191128\%20(2).pdf> Acesso em: 10 jun 2021.

D'AGOSTINI, Adriana; TITTON, Mauro. Política de formação de professores para educação do campo: limites e possibilidades. Germinal: Marxismo e Educação em Debate, Salvador, v. 6, n. 1, p. 155-173, dez. 2014. ISSN 2175-5604. Disponível em:

https://portalseer.ufba.br/index.php/revistagerminal/article/view/10218>. Acesso em: 22 Mar. 2020. doi: http://dx.doi.org/10.9771/gmed.v6i1.10218.

DINIZ, Daise Ferreira. O programa nacional de educação na reforma agrária (PRONERA) no contexto do estado democrático de direito: movimentos sociais e gestão participativa. In: $37^{a}$ Reunião Nacional da ANPEd. 2015. p. 20-20.

FERRANTE, V. L. S.B.; BERGAMASCO, S. M. P. P., Censo de Assentamentos rurais do Estado de São Paulo. Análise e Avaliação dos Projetos de Assentamentos do Estado de São Paulo, Pesquisa MULTICAMPI/UNESP, Araraquara, janeiro/1995.

MACHADO, V. A escola e o meio rural: um estudo acerca da concepção de educação entre jovens assentados. In: Fábio Fernandes Villela. (Org.). Educação, Trabalho e Saúde no Campo. 1ed.São José do Rio Preto: HN Editora, 2015, v. 1, p. 51-78.

MARTINS, Fernando José. A escola e a educação do campo. São Paulo: Pimenta Cultural, 2020.

MOLINA, Monica C.; ANTUNES-ROCHA, Isabel. Educação do Campo: história, práticas e desafios no âmbito das políticas de formação de educadores-reflexões sobre o PRONERA e o PROCAMPO. Reflexão e Ação, v. 22, n. 2, p. 220-253, 2014.

MOLINA, Mônica Castagna. Contribuições das licenciaturas em educação no campo para as políticas de formação de educadores. Educ. Soc., Campinas, v. 38, nº. 140, p.587-609, jul.-set., 2017. Disponível em http:/ /www.scielo.br/pdf/es/v38n140/1678-4626-es-38-140-00587.pdf. Acesso em: 22 mar. 2020. 
MST. Nossa concepção de educação e de escola. IN: Caderno de Educação nº 13. Dossiê MST Escola. $1^{a}$ ed. São Paulo. 2005.

OLIVEIRA, D. A. ; MACHADO, V. . O Sistema do Complexo Temático como alternativa pedagógica para escolas de assentamentos rurais. Iniciação Científica (CESUMAR), v. 22, p. 247259, 2020. Disponível em:

https://periodicos.unicesumar.edu.br/index.php/iccesumar/article/view/9220/6478 Acesso em 22 mar. 2020.

OLIVEIRA, Danielle Arena de. A educação do campo e a estratégia de projetos: a construção de uma prática pedagógica transformadora. 2017. Dissertação (Mestrado em Mestrado Profissional em Docência para a Educação Básica) - Universidade Estadual Paulista, 2017.

RAVANELI, Karla Aparecida de Ataíde. Educação do Campo: a representatividade da mulher no material didático do PNLD/Campo. Iniciação Científica. Relatório de Pesquisa, Conselho Nacional de Desenvolvimento Científico e Tecnológico. Unesp: Bauru. 2019.

SANTOS Ramofly Bicalho dos; SILVA Marizete Andrade da. Políticas públicas em educação do campo: Pronera, Procampo e Pronacampo, Revista Eletrônica de Educaşão, v. 10, n. 2, p. 135-144, 2016. Disponível em:

file:///C:/Users/Vitor/Desktop/ARTIGO\%20AMANDA/1549-9859-1-PB.pdf Acesso em 20 jun 2021.

VIGHI, Cátia Simone Becker. Formação docente: a educação do campo em foco. Formação Docente-Revista Brasileira de Pesquisa sobre Formação de Professores, v. 7, n. 13, p. 115-132, 2015. Disponível em: https:/ / revformacaodocente.com.br/index.php/rbpfp/article/view/126/115. Acesso em: 22 set. 2020. 